Asian J. Med. Biol. Res. 2020, 6 (2), 155-167; doi: 10.3329/ajmbr.v6i2.48046

\author{
Asian Journal of \\ Medical and Biological Research \\ ISSN 2411-4472 (Print) 2412-5571 (Online) \\ www.ebupress.com/journal/ajmbr
}

\title{
Article \\ Humoral immune response against Newcastle disease virus and its pathological changes in vaccinated chickens in selected areas of Barisal district in Bangladesh
}

\author{
Nasrin Akter Sumona ${ }^{1}$, Khondoker Jahengir Alam ${ }^{1^{*}}$, Md. Yeasin $\operatorname{Arafat}^{2}$ and $\operatorname{Imam~Hasan~}^{3}$ \\ ${ }^{1}$ Department of Pathology and Parasitology, Patuakhali Science and Technology University, Patuakhali, \\ Bangladesh \\ ${ }^{2}$ Department of Microbiology and Public Health, Patuakhali Science and Technology University, Patuakhali, \\ Bangladesh \\ ${ }^{3}$ Department of Anatomy and Histology, Faculty of Veterinary Science, Bangladesh Agricultural University, \\ Mymensingh-2202, Bangladesh
}

*Corresponding author: Professor Dr. Khondoker Jahengir Alam, Department of Pathology and Parasitology, Patuakhali Science and Technology University, Bangladesh. E-mail: khondoker.pstu@ gmail.com

Received: 20 March 2020/Accepted: 06 May 2020/ Published: 30 June 2020

\begin{abstract}
The objectives of this study were to evaluate humoral immunity against Newcastle disease (ND) virus in vaccinated chickens in terms of serum $\mathrm{HI}$ antibody titers in broiler and layer chickens and to determine pathological changes in vaccinated chickens. A total of 240 serum samples were collected from broiler (135) and layer (105) chickens from Barishal Sadar, Babugonj and Gournadi Upazilas of Barishal district in Bangladesh after two weeks of scheduled vaccination programme. The overall detection of Hemagglutination inhibition (HI) antibodies against Newcastle disease virus was $62.2 \%$ in broiler and $83.8 \%$ in layer chickens. The percentages of specific HI antibody titer in broiler chickens were 57.5, 70 and 48 in 1-2 weeks, 3-4 weeks, and 4-above weeks age groups respectively where in layer chickens were 85, 80, 90, 80 and 80 in 15-24 weeks, 25-34 weeks, 35-44 weeks, 45-54 weeks and > 55 weeks of age groups respectively. For both broiler and layer chicken's protective antibody titers were found higher in adult than in young chickens. Out of 240 samples HI titers of $172(71.67 \%)$ samples were found at protective level, $42(17.5 \%)$ samples were at marginal level and 26 (10.83\%) samples were below protective level. Among 26 samples of non-protective level, 21 were broiler and 5 were layer chicken. Out of 26 samples, $10(38.46 \%)$ were found apparently infected with NDV where 8 (38.09\%) were broiler and $2(40 \%)$ were layer. The apparently infected birds were diagnosed on the basis of postmortem findings and histopathological lesions. Results of the present investigation may help to design appropriate vaccination schedule for ND in broiler and layer chickens and thus to protect chickens from ND in field condition.
\end{abstract}

Keywords: hemagglutination inhibition (HI) test; Newcastle disease virus; vaccine; serum HI antibody

\section{Introduction}

Newcastle disease (ND) is also known as ranikhet disease. It is considered as one of the major problems towards the development of poultry industry in Bangladesh. Newcastle disease (ND) is a highly contagious viral infection of avian species especially poultry caused by Newcastle Disease virus (NDV), a Paramyxovirus called avian Paramyxovirus type 1 (APMV-1). NDV has been classified into three pathotypes based on the virulence in infected birds as mild lentogenic form; moderate mesogenic and severe velogenic form which occur as viscerotrophic or neurotrophic form. Most of infection caused by velogenic strains rather than mesogenic and lentogenic strains. In Bangladesh particular, ND is one of the most important devastating poultry diseases that causes great losses to commercial and local poultry farmers (Illango et al., 2003). It affects almost all species of birds causing a highly contagious and rapidly spreading disease with high morbidity and mortality and severe drop in egg production. Signs of the disease usually vary in severity and lethality, but usually include respiratory 
distress, diarrhea, circulatory disturbances and central nervous system impairment (Alexander, 2003). Birds become emaciated with ruffled feathers and greenish material soiled vents. Post mortem examination revealed ulcers in intestine, hemorrhages in proventriculus and caecal tonsils, congestion and hemorrhages in trachea, lung, liver and heart, enlarged and mottled spleen. In Africa and Asia ND is a major constraint to the development of both industrial and village poultry production (Alders et al., 2001). NDV infections of poultry range from latent to rapidly fatal depending upon the pathotype of virus involved (Alexander, 2003). The transmission of NDV occurs through newly introduced birds, selling or giving away sick birds, exposure to fecal and other excretions from infected birds and contact with contaminated feed, water, equipment and clothing (Tu et al., 1998). The disease causes high economic losses due to high mortality, morbidity, stress, decreased egg production and hatchability (Alexander, 2000).

Newcastle disease remains a major concern to the poultry industry; however, it can be managed with effective vaccination programs (Martinez et al., 2018). Appropriate vaccination and subsequent effective immune response are known to be the only safeguard measure to avoid outbreaks; however, evaluation of protective immune response is not well in practice in Bangladesh (Munir et al., 2012). Newcastle disease can be controlled by vaccination of birds at risk that may be a successful intervention strategy (Veits et al., 2006). In Bangladesh both live and killed NDV vaccine are issued by many pharmaceutical companies. The current vaccination schedule is directed by the Department of Livestock Services (DLS). They issue two types of live vaccine all over the country. Live lentogenic vaccine (BCRDV) of F-strain is administered by intra-ocular instillation to chicks. Followed by BCRDV live mesogenic vaccine (RDV) of M-strain is administered by intramuscular injection at 21 days old chicks which is repeated at every six months interval.

Despite the wide use of the commercially available vaccines, ND vaccines are less effective in some cases, such as for immature or elderly individuals, age at vaccination (Maeda et al., 2004) under conditions of environmental stress and because of immunosuppression (Saif, 1998). The aim of this study was to evaluate the HI antibody titers as well as to observe the pathological changes in vaccinated chickens infected with NDV under field condition at Barishal district.

\section{Methods and Materials}

The present study was performed at the Department of Pathology and Parasitology, Faculty of Animal Science and Veterinary Medicine, Patuakhali Science and Technology University (PSTU) during the period from February 2018 to February 2019. The present investigation was carried at Barishal sadar, Babugonj and Gournadi Upazilas of Barishal district in Bangladesh.

\subsection{Experimental design and treatments}

Nine (09) commercial farms (Broiler 05 and layer 04) were randomly selected from three different Upazila of Barisal district. A total of 240 serum samples were collected randomly from broiler (135) and layer (105) chickens. After two weeks of immunization with commercial ND vaccines (ND virus strain Clone 30), blood samples were collected for sera. In case of broiler, 1-2 weeks, 3-4 weeks and > 4 weeks of age group and in case of layer, 15-24 weeks, 25-34 weeks, 35-44 weeks, 45-54 weeks and > 55 weeks age groups were selected for determination of age wise HI antibody titers. HI test was performed using 4 HA unit of Newcastle disease virus (NDV) antigen to detect ND specific HI antibodies in vaccinated chickens.

\subsection{Blood collection and serum preparation}

A total of 240 blood samples were collected aseptically from the wing vein of birds (from commercial layer and broiler). Then the samples were kept at room temperature for two hours to clot blood inside the syringe. After clotting, fluid portion of blood were placed in graduated centrifuge tubes and centrifuged at $2500 \mathrm{rpm}$ for 5 minutes. The clear sera samples were poured in eppendorf tube which was labeled and stored at $-20^{\circ} \mathrm{C}$ in freezer of the Laboratory. All the serum samples were analyzed for NDV antibodies by HI test.

\subsection{Preparation of chicken red blood cell (RBC) suspension (1\% v/v)}

To prepare RBC suspension in PBS, a total of $3 \mathrm{ml}$ of blood were collected from the wing vein of a healthy unvaccinated chicken aseptically in a disposable syringe containing $3 \mathrm{ml}$ of Alsever's solution as anticoagulant. The blood was placed in a centrifuge tube from the syringe and was centrifuged at $1500 \mathrm{rpm}$ for 15 minutes. The plasma and buffy coat were removed carefully with a pipette. After washing three times with phosphate buffered saline (PBS), 1\% suspension of RBC in PBS (1 $\mathrm{ml}$ suspension+ $99 \mathrm{ml} \mathrm{PBS}$ ) was prepared for HI test. 


\subsection{Hemagglutination test and determination of $4 \mathrm{HA}$ unit virus for $\mathrm{HI}$ test}

The HA test is used to standardize the antigens for the HI test. $50 \mu \mathrm{l}$ PBS was dispensed into a row of 12 wells in a V-bottomed microtiter plates for each antigen used in the test. One additional row of wells was included for a positive HA control. $50 \mu \mathrm{l}$ undiluted antigen was added to the 1st well of each corresponding row. The antigen (first through 11th well) was serially diluted with a multichannel micro pipette set to deliver $50 \mu$ l. The resulting dilutions was range from 1:2 in the first well, to 1:2048 in the 11th well; the 12th row, containing only PBS, was serve as a cell control. $50 \mu 1 \%$ erythrocyte suspension was added to each well and shake/agitate the plate to thoroughly mix reactants. The microtiter plate was covered with sealing tape and incubated at room temperature until a distinct button was formed in the cell control well (usually takes 20 to $30 \mathrm{~min}$ ). The endpoint of the titration was the highest dilution of antigen causing complete hemagglutination. The endpoint dilution was considered 1 HA unit (HAU); 4 HA units in $50 \mu \mathrm{l}$ were used in the HI test. The dilution containing 4 HA units was determined by dividing the endpoint by 8 (the desired number of HAUs), e.g. if the HA endpoint titer was $1: 256$, the dilution which would contain $4 \mathrm{HA}$ units in $50 \mu 1$ would be $1: 32(256 \div 8)$. Appropriate quantities of 4 HAU antigen was made by diluting the antigen with PBS.

\subsection{Hemagglutination inhibition (HI) test}

HI test was done according to the procedure of OIE (2012). For HI test, two-fold serial dilution of $25 \mu 1$ serum was made with PBS in V-bottomed microtiter plates (Nunc) up to 10th well with multichannel pipette. $25 \mu 1$ of 4 hemagglutinating (HA) units of Newcastle disease virus or antigen was added up to 11th well. To facilitate antigen antibody reaction the plates were kept at room temperature for more than 30 minutes. Then $25 \mu \mathrm{l}$ of $1 \%$ (v/v) chicken RBC suspension was added to each well. The 11th well considered as positive control that contains antigen and RBCs and the 12th well considered as the negative control that contains only RBCs. After gentle mixing, the RBCs were allowed to settle at room temperature for 40 minutes. Agglutination was assessed by tilting the plates. The samples showing peculiar central button shaped settling of RBCs were recorded as positive and highest dilution of each sample causing hemagglutination inhibition was considered as the end point, which was used to estimate the HI titer. The HI titer of each serum sample was expressed as reciprocal of the serum dilution. Four $\log _{2} \mathrm{HI}$ titer to NDV was considered as the protective threshold against ND; titer below this was categorized as non-protective (OIE, 2012).

\subsection{Histopathological examination}

Postmortem examination and diagnosis of the Newcastle diseases of in vaccinated chickens below protective level was done by following the standard procedures. After dissecting the dead birds, samples were incised with sterile scissors. All samples (liver, heart, spleen, lungs, trachea, intestine, proventiculus, cecal tonsil etc.) were collected after postmortem examination of infected birds below protective level from nine commercial poultry farms. After collection of samples, it was preserved in $10 \%$ neutral buffered formalin solution for further histopathological examination. Formalin fixed tissue samples were processed and stained as per standard method (Titford, 2009).

\subsection{Statistical analysis}

All data were summarized with the help of MS Excel and analyzed by means of the GraphPad Prism 5.0 statistical software (GraphPad Software, San Diego, USA). Differences with a P value $<0.05$ were regarded as statistically significant.

\section{Results}

\subsection{NDV specific HI antibody titers in vaccinated broiler chickens}

A total of 135 serum samples were collected from different commercial broiler farms which were subjected to $\mathrm{HI}$ test. Out of them, HI antibody titers of 21 samples (15.6\%) were found below protective level $\left(2^{1}-2^{2}\right), 30$ samples $(22.2 \%)$ were found at marginal level $\left(2^{3}\right)$ and 84 samples $(62.2 \%)$ were found at protective level $\left(2^{4}\right.$ $2^{10}$ ) (Table 2). In 1-2 weeks of age HI antibody titers varied from $2^{1}$ to $2^{6}$ and their respective percentages were $5,20,17.5,25,30$ and 2.5 with a mean of $17.43( \pm 11.86)$ and GMT of 6.03. However, in 3-4 weeks of age HI antibody titers varied from $2^{2}$ to $2^{7}$ and their respective percentages were 8.56, 20,32.9, 22.9, 12.85 and 2.86 with a mean of $26.13( \pm 23.23)$ and GMT of 8.34 (Table 1). On the other hand, in 4-above weeks of age HI antibody titers were varied from $2^{2}$ to $2^{6}$ and their respective percentages were 20,36, 24, 16 and 4 with a mean of $16.14( \pm 13.56)$ and GMT of 5.72 (Table 1$)$. The protective antibody titers were recorded in $57.5 \%, 70 \%$ and $48 \%$ chickens at the age of 1-2 weeks, 3-4 weeks and 4-above weeks respectively (Table 2). 
3.2. NDV specific HI antibody titers in vaccinated layer chickens

A total of 105 serum samples were collected from different commercial layer farms which were subjected to HI test. Among them, HI titers of 5 samples $(4.76 \%)$ were found below protective level $\left(2^{1}-2^{2}\right)$, 12 samples $(11.43 \%)$ were found at marginal level $\left(2^{3}\right)$ and 88 samples $(83.8 \%)$ were found at protective level $\left(2^{4}-2^{10}\right)$ (Table 4). HI antibody titers among different age groups of commercial layer chickens were also examined in details. In 15-24, 25-34, 35-44, 45-54 and > 55 weeks of age groups, HI antibody titers varied from $2^{2}$ to $2^{10}$. In 15-24, 25-34, 35-44 weeks of age $\mathrm{HI}$ antibody titers varied from $2^{2}$ to $2^{9}$ and their respective percentages were $5,5,15,15,15,20,20$ and $5 ; 5,10,15,15,15,15,20$ and 5; 3.33, 3.33, 10, 13.33, 20, 23.33, 23.33 and 3.33 with a mean of $126.3( \pm 93.8), 120.2( \pm 95.2), 132.9( \pm 91.4)$ respectively (Table 3$)$ and protective antibody titer percentage were $85 \%, 80 \%$ and $90 \%$ respectively (Table 4). In 45-54 and 55-above weeks of age HI antibody titers varied from $2^{2}$ to $2^{10}$ and their respective percentages were 6.67, 6.67, 6.67, 13.33, 13.33, 20, 20, 6.67, 6.67 and $5,5,10,15,15,26.67,26.67,5,5$ with the mean of $145.2( \pm 103.3)$ and $161.4( \pm 130.2)$ and the protective antibody titer percentage were $80 \%$ and $80 \%$ for $45-54$ and 55 -above weeks of age groups respectively (Table 4). The GMT were found 37.531, 37.213, 48.671, 50.023 and 51.186 for 15-24, 25-34, 3544, 45-54 and 55- above age groups respectively (Table 3).

\subsection{Prevalence of ND in vaccinated chickens having specific $\mathrm{HI}$ antibody below protective level}

The Prevalence of Newcastle disease below protective level in vaccinated chickens, a total number of 26 chickens were examined from 9 different poultry farms of Barisal district during the period of February 2018 to February 2019 and out of which 10 cases were found positive for Newcastle disease (Table 5).

\subsection{Prevalence of ND in vaccinated chickens having specific HI antibody below protective level in different poultry types}

The Prevalence of ND below protective level in vaccinated chickens in different poultry breeds at Barishal district was shown in Table 6. According to this results, prevalence of ND was higher in layer (40\%) than broiler $(38.09 \%)$ chickens.

\subsection{Gross observation in Newcastle disease virus infected chickens}

Pin point hemorrhages were found in the tip of the glands of proventiculus and glands become swollen with catarrhal exudation called catarrhal proventriculitis (Figure 1). Button like ulcers were found in intestine of chickens. Severe hemorrhages in the intestine (Figure 2). Hemorrhage was found in caecal tonsil of Newcastle disease affected chickens. Cecal tonsil showed typhlitis on every sample (Figure 3). Necrotic foci in liver was found ND affected chickens (Figure 4). Spleens of infected chickens were dark in colour and enlarged (Figure 5). Trachea observation revealed catarrhal tracheitis (Figure 6). Severe congestion of lungs was found in ND affected chickens. Lungs were edematous (Figure 7). Epicarditis and myocarditis were observed. Myocardium degeneration of heart. In layer chicken, it was accompanied by pericarditis (Figure 8).

\subsection{Histopathological observation in Newcastle disease virus infected chickens}

Hemorrhages and necrosis were seen in the mucosa and submucosa of proventiculus. Desquamation of proventriculus epithelial layer. Globular destruction of proventiculas surface, hyperemia of the muscularis layer and infiltration of inflammatory cells to submucosal layer of proventriculus glands (Figure 9). Intestinal villi were blunted and necrosis of sub mucosa. Mononuclear cell infiltration in the lamina propria. Degeneration and necrosis of the intestinal villi with tendency of sloughing (Figure 10). Hemorrhages, congestion and necrosis were found in epithelial mucosal cell. Infiltration of inflammatory cell into the submucosal layer (Figure 11). Liver showed degeneration and multifocal necrosis in broiler chicken, while in layer chicken they were accompanied by perihepatitis. Hemorrhage, necrosis, and multifocal inflammatory cell infiltration (Figure 12). Decreased number of lymphocytes in peri arterial lymphotic sheath of spleen was shown in Newcastle disease infected chickens. Lymphoid depletion was observed in spleen (Figure 13). Trachea showed congestion, hemorrhage, mononuclear inflammatory cell infiltration in subepithelial layer were observed, and edema at almost every trachea sample. Degeneration and necrosis of tracheal epithelium along with hemorrhages (Figure 14). Congestion, edema, and mononuclear inflammatory infiltration at the inside and the wall of alveoli were found in ND affected chickens (Figure 15). Degeneration, necrosis and edema with mononuclear cell infiltration. Congestion and foci of inflammatory cells were observed in the hepatic parenchyma. Hepatocytes showed mild to moderate fatty change (Figure 16) 
Table 1. Distribution of HI antibody titers against NDV in serum samples of vaccinated broiler chickens.

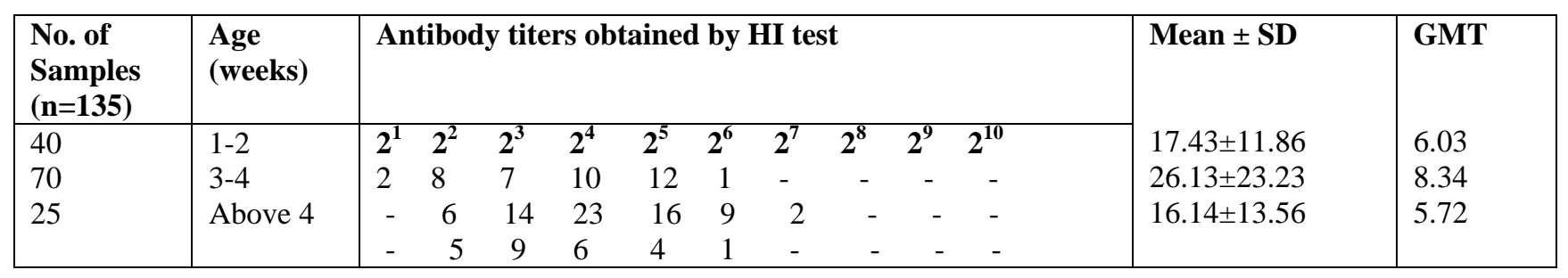

Table 2. Protection level of $\mathrm{HI}$ antibody titer against NDV in vaccinated broiler chickens according to age group.

\begin{tabular}{|l|l|l|l|}
\hline Age (weeks) & \multicolumn{3}{|c|}{ Protection level of HI antibody titer (\%) } \\
\hline & Below Protection level $\left(\mathbf{2}^{\mathbf{1}} \mathbf{2}^{\mathbf{2}}\right)$ & Marginal level $\left(\mathbf{2}^{\mathbf{3}}\right)$ & Protection level $\left(\mathbf{2}^{\mathbf{4}}-\mathbf{2}^{\mathbf{1 0}}\right)$ \\
\hline $1-2$ & $10(25 \%)$ & $7(17.5 \%)$ & $23(57.5 \%)$ \\
\hline $3-4$ & $6(8.57 \%)$ & $15(21.4 \%)$ & $49(70 \%)$ \\
\hline $4-$ above & $5(20 \%)$ & $8(32 \%)$ & $12(48 \%)$ \\
\hline
\end{tabular}

Table 3. Distribution of HI antibody titers against NDV in serum samples of vaccinated layer chickens.

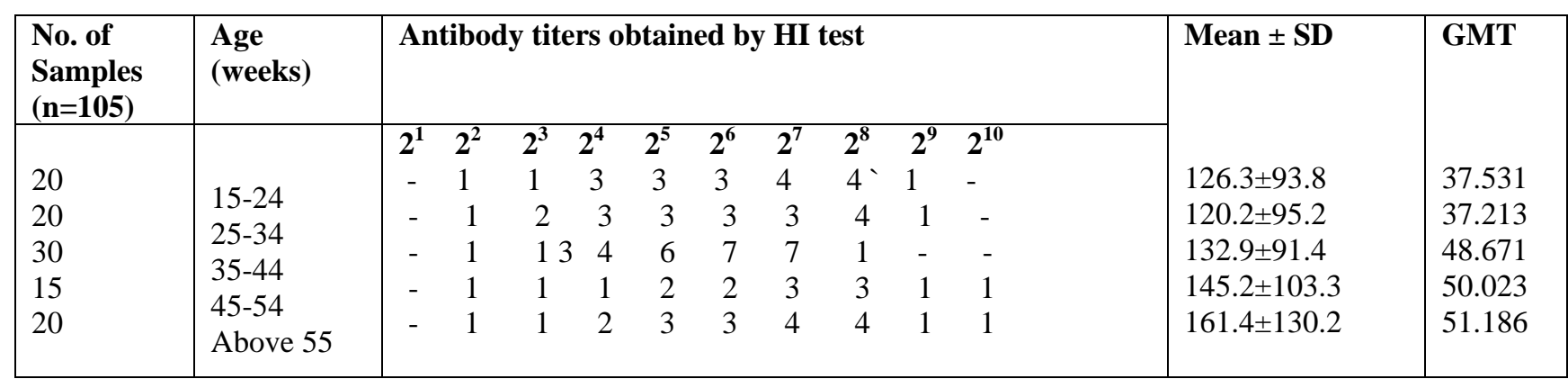

Table 4. Protection level of HI antibody titer against NDV in vaccinated layer chickens according to age group.

\begin{tabular}{|l|l|l|l|}
\hline \multirow{2}{*}{$\begin{array}{l}\text { Age } \\
(\text { weeks })\end{array}$} & \multicolumn{3}{|c|}{ Protection level of HI antibody titer (\%) } \\
\cline { 2 - 4 } & Below Protection level $\left(\mathbf{2}^{\mathbf{1}} \mathbf{2}^{\mathbf{2}}\right)$ & Marginal level $\left(\mathbf{2}^{\mathbf{3}}\right)$ & Protection level $\left(\mathbf{2}^{\mathbf{4}} \mathbf{2}^{\mathbf{1 0}}\right)$ \\
\hline $\mathbf{1 5 - 2 4}$ & $1(5 \%)$ & $2(10 \%)$ & $17(85 \%)$ \\
\hline $\mathbf{2 5 - 3 4}$ & $1(5 \%)$ & $3(15 \%)$ & $16(80 \%)$ \\
\hline $\mathbf{3 5 - 4 4}$ & $1(3.3 \%)$ & $2(6.67 \%)$ & $27(90 \%)$ \\
\hline $\mathbf{4 5 - 5 4}$ & $1(6.67 \%)$ & $2(13.33 \%)$ & $12(80 \%)$ \\
\hline $\mathbf{5 5 - a b o v e}$ & $1(5 \%)$ & $3(15 \%)$ & $16(80 \%)$ \\
\hline
\end{tabular}

Table 5. Overall prevalence of ND in vaccinated chickens having specific HI antibody below protective level.

\begin{tabular}{|l|l|l|}
\hline $\begin{array}{l}\text { Total no. of chickens below } \\
\text { protective level }\end{array}$ & $\begin{array}{l}\text { Total no. of infected below protective } \\
\text { level }\end{array}$ & Prevalence \\
\hline 26 & 10 & $38.46 \%$ \\
\hline
\end{tabular}

Table 6. Prevalence of ND in vaccinated chickens having specific HI antibody below protective level in different poultry types.

\begin{tabular}{|l|l|l|l|}
\hline Type of Bird & $\begin{array}{l}\text { No of examined chickens below } \\
\text { protective level }\end{array}$ & $\begin{array}{l}\text { No of infected chickens below } \\
\text { protective level }\end{array}$ & Prevalence \\
\hline Broiler & 21 & 8 & $38.09 \%$ \\
\hline Layer & 5 & 2 & $40 \%$ \\
\hline
\end{tabular}




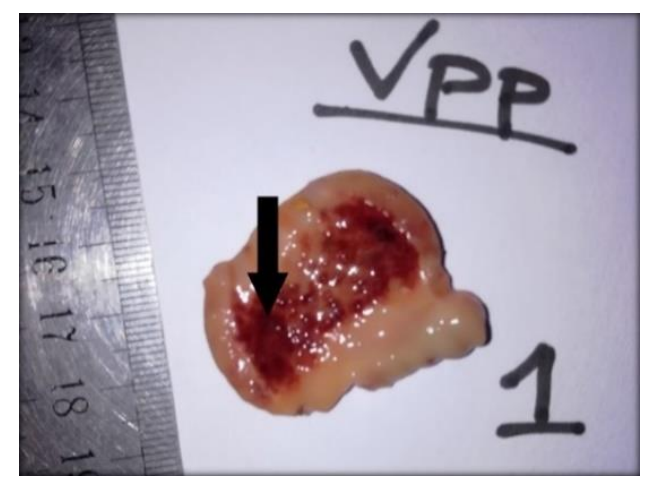

Figure 1. Proventiculus of 14 days old NDV infected chickens showing pin point hemorrhage on tip of the glands.

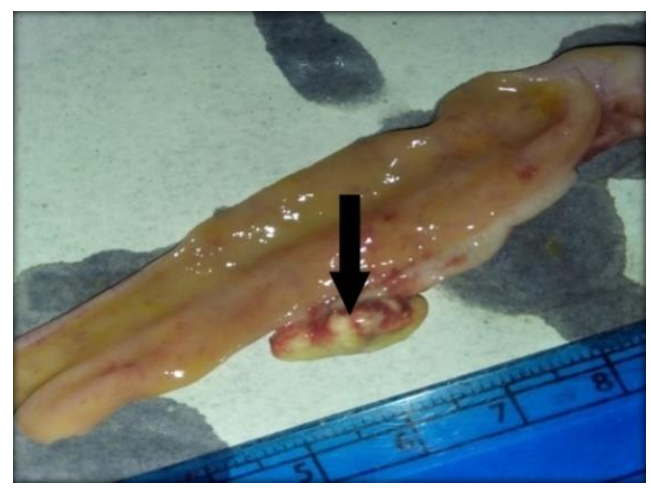

Figure 2. 12 days old NDV infected broiler chicken showing hemorrhages in intestinal mucosa.

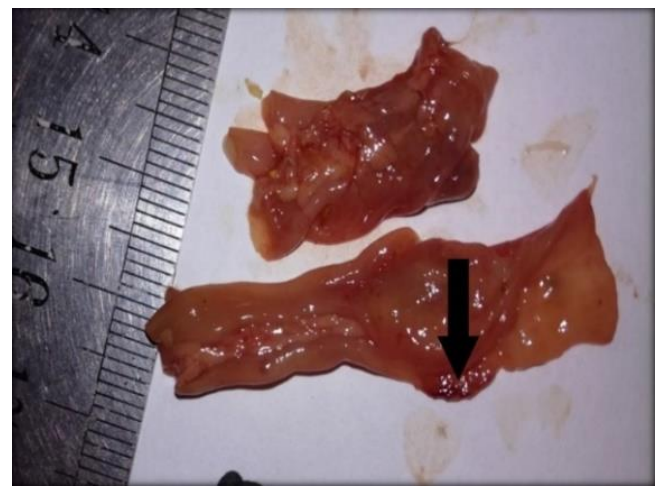

Figure 3. 16 weeks old NDV infected layer chicken showing enlarged and hemorrhagic cecal tonsil.

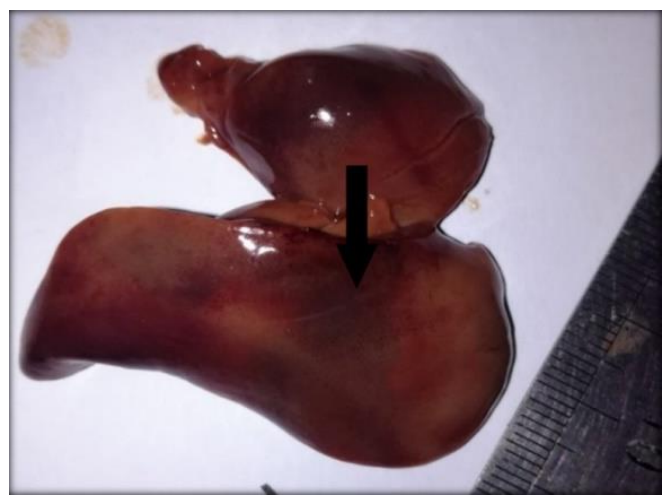

Figure 4. 32 weeks old NDV infected layer chickens showing hepatic necrosis and hemorrhage in liver. 


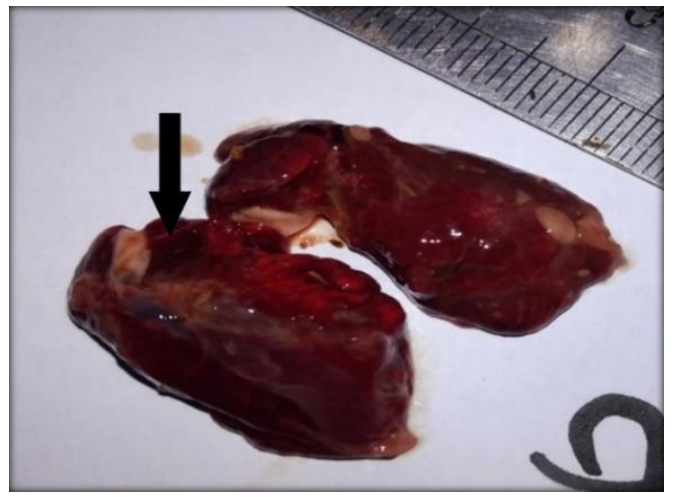

Figure 5. 25 days old NDV infected broiler chicken showing severe congestion, hemorrhages and edema in lungs.

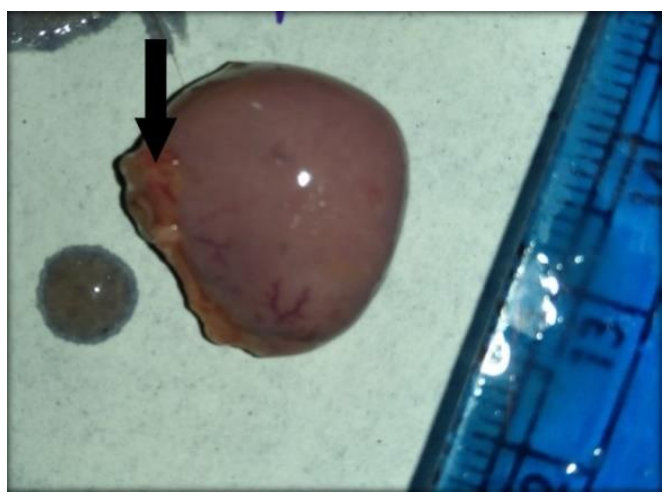

Figure 6. 45 weeks old NDV infected layer chickens showing enlargement and hemorrhage in spleen.

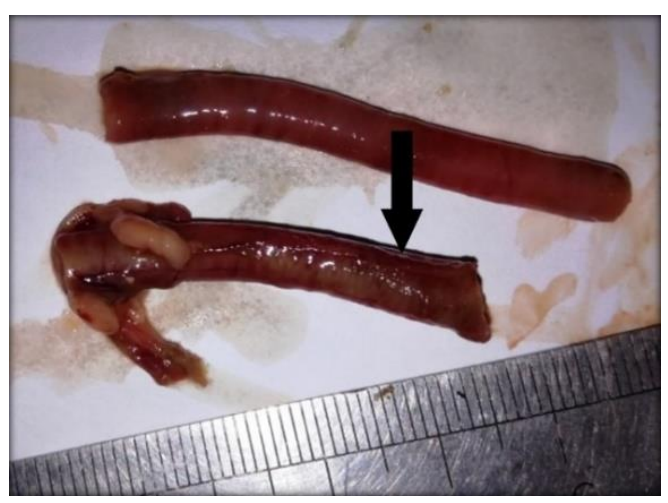

Figure 7.21 days old NDV infected broiler chicken showing hemorrhages and congestion in trachea.

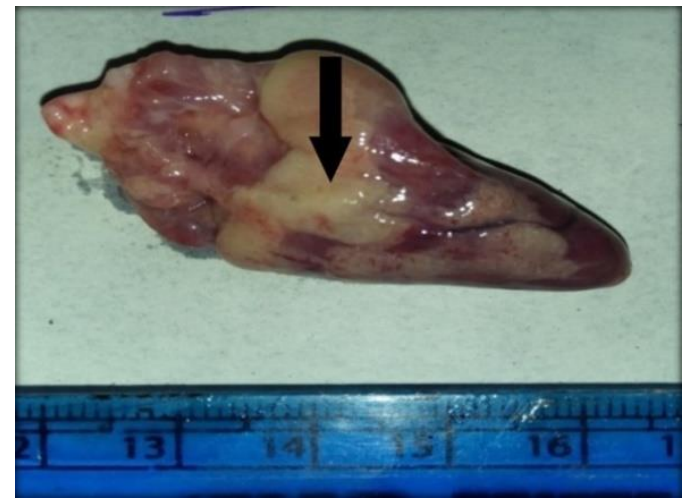

Figure 8. 48 weeks old NDV infected layer chicken showing hemorrhage and inflammation in heart. 


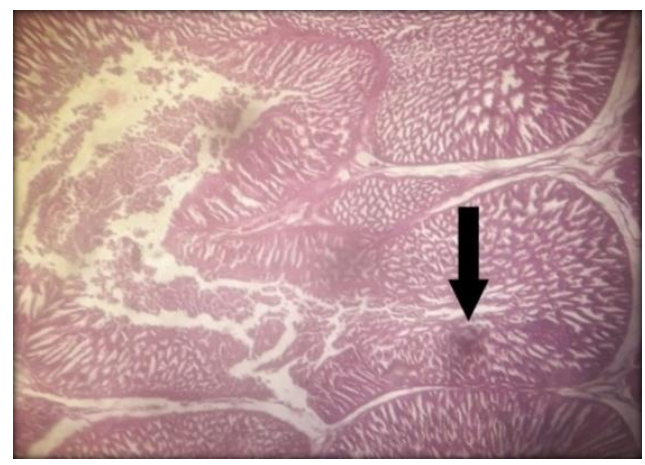

Figure 9. Proventriculus of 14 days old NDV infected broiler chicken showing hemorrhage and necrosis with infiltration of inflammatory cells $(\mathrm{H} \& \mathrm{E}$ X640).

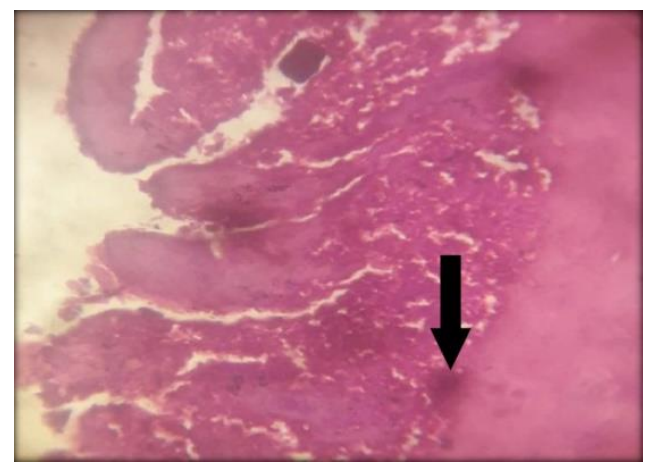

Figure 10. 12 days old NDV infected chickens showing blunted intestinal villi and necrosis of sub mucosa in the intestine (H\& E X 640).

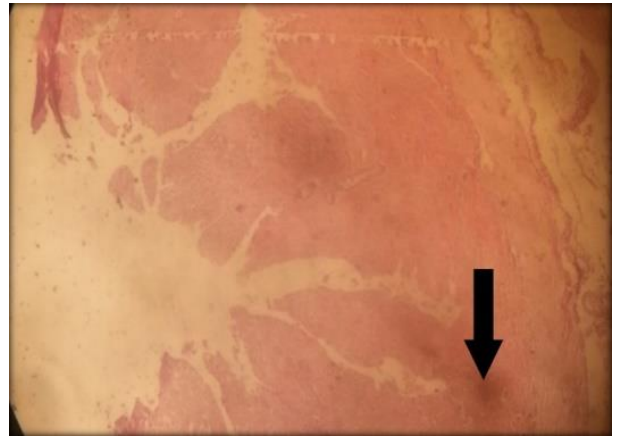

Figure 11. 16 weeks old NDV infected layer chickens showing hemorrhages, congestion and necrosis in epithelial layer and inflammatory infiltration in cecal tonsil (H \& E X640).

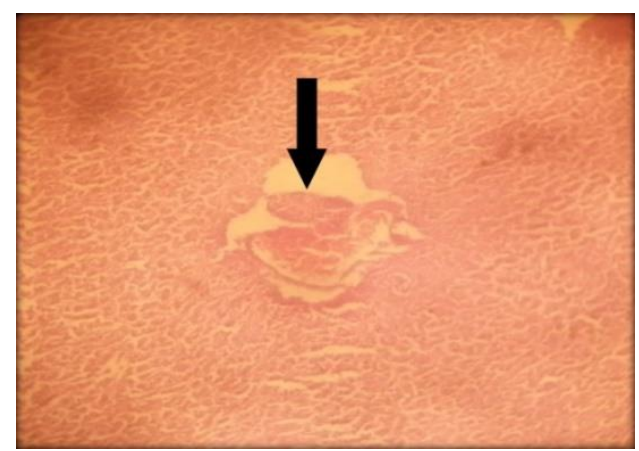

Figure 12. Liver of 32 weeks old NDV infected chickens showing hemorrhage, necrosis, and multifocal inflammatory cell infiltration (H\&E X 640). 


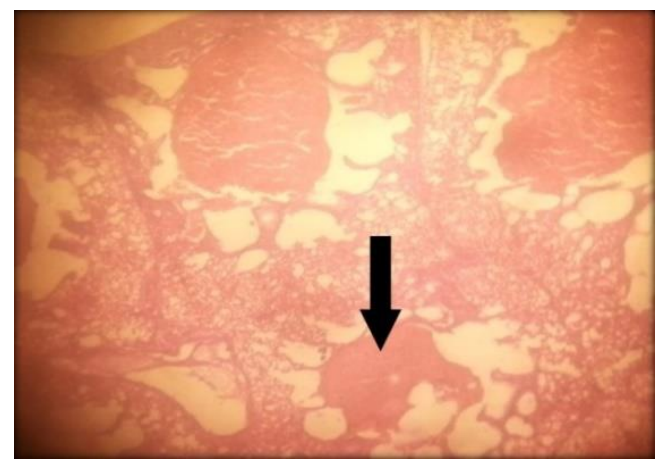

Figure 13. Lung of 25 days old NDV infected broiler chickens showing congestion of blood vessels and infiltration of inflammatory cells in alveoli (H \& E X 640).

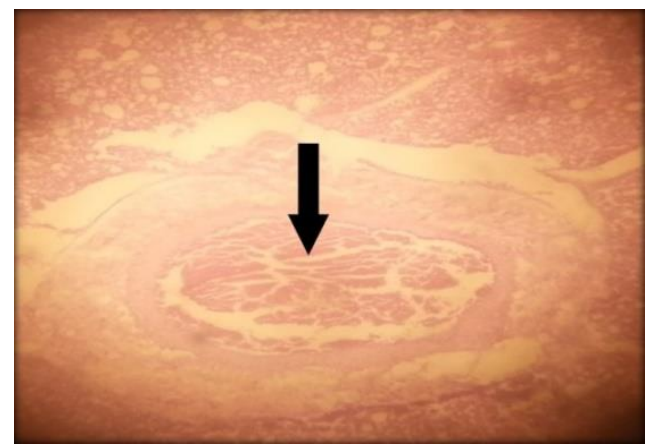

Figure 14. Spleen of 45 weeks old layer chicken infected with NDV showing decreased lymphocytes in periarterial lymphatic sheath (H\&E X 640).

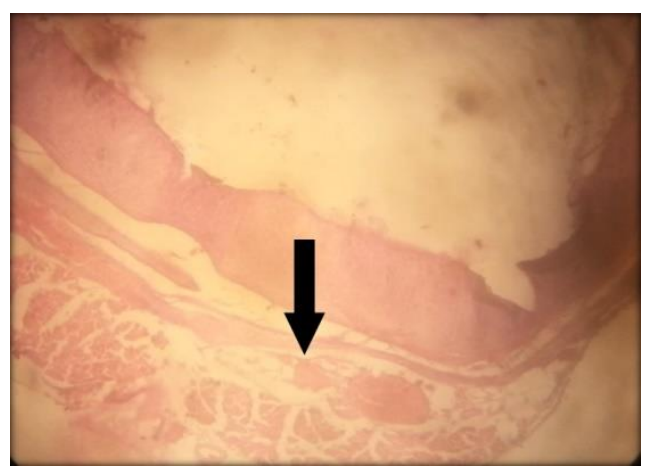

Figure 15. Trachea of 21 days old broiler chicken showing congestion, hemorrhage, mononuclear inflammatory cell infiltration in sub epithelial layer (H\& E X 640).

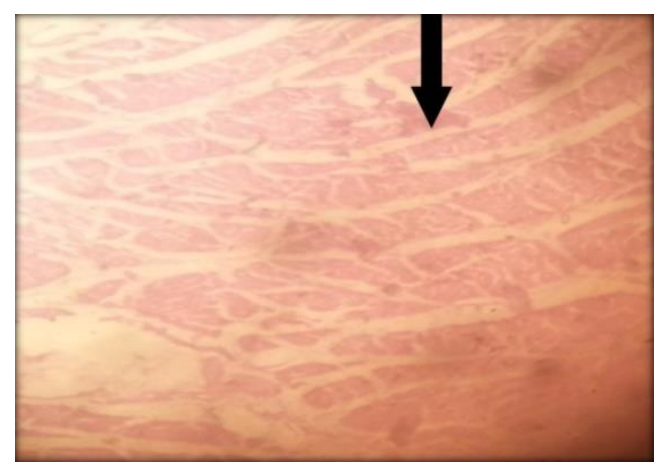

Figure 16. Degeneration, necrosis and edema with mononuclear cell infiltration in hepatic parenchyma (H\& E X 640). 


\section{Discussion}

Newcastle diseases is a highly contagious viral disease of chickens produce major constraint against the development of poultry industry. In this study, an attempt was undertaken for evaluation of humoral immunity against Newcastle disease virus and its pathological changes in vaccinated chickens at Barishal district of Bangladesh; however the HI antibody titers in NDV vaccinated broiler and layer chickens were determined and chickens below protective HI titer level were grossly and microscopically examined. The HI titer below protective level may be found due to vaccination failure or presence of maternally derived antibody (MDA) which neutralizes vaccine virus. Protective level of HI antibody titer indicates that the commercial vaccines worked well to immunize chickens against ND.

\subsection{NDV specific HI antibody titers in vaccinated broiler chickens}

In the study, $62.2 \%$ samples of broilers were positive for NDV antibodies which is similar to the reports of Husna et al. (2016) who reported 62.4\% samples of broilers were positive for NDV antibodies in Bangladesh. On the other hand, the recorded protective HI titer level was lower than the previous study, reported by Rahman et al. (2017), Mozaffor et al. (2010) and Numan et al. (2005) where the reported the protective titer were 85.9\%, $78.04 \%$ and $98.07 \%$. An opposed to, the protective HI titer level (62.2\%) was more than that reported by Bell and Moulodi (1988) who recorded the antibody levels against NDV in different regions of Morocco ranging from 5 to $83 \%$ (average 35\%) of the chickens sampled. The antibody titers in 3-4 weeks of age is higher which might be due to low levels of MDA. Mozaffor et al. (2010) reported that GMT was 7.47 at 3- 4weeks of age of broiler in Bangladesh which is slightly lower from the present study. They also reported that GMT was 12.78 at 1-2 weeks of age of broiler in Bangladesh which is higher from the present study. In the present study, the birds in 3-4 weeks of age showed the highest level of antibody titers (GMT 8.34) and showed relatively low susceptibility to clinical infection. On the other hand, the birds within 1-2 weeks of age showed intermediary level of serum antibody titers (GMT 6.03). This level is unexpected, since we expected that through vaccination the level of serum antibody titers should increase at this age. Furthermore, the birds within $>4$ weeks of age showed low level of serum antibody titers (GMT 5.72) than the previous two groups and showed relatively high susceptibility to clinical infection.

In this investigation, this variation might be due to poor biosecurity and poultry immunization, poor quality of vaccine, unsuitable vaccination schedule, inappropriate methods of vaccination, application of expired vaccine, presence of immunosuppressive substances in the feed or immunosuppressive diseases, treatment with antibiotics during vaccination have been also reported as the other possible causes for the vaccine failure in developing countries (Sil et al., 2002; Vui et al., 2002).

\subsection{NDV specific HI antibody titers in vaccinated layer chickens}

In the study, $83.8 \%$ samples of layers were positive for NDV antibodies which is slightly lower than the recent reports of Husna et al. (2016) who reported $94.4 \%$ samples of layer were positive for NDV antibodies in Bangladesh. From another point of view, the recorded protective HI titer level was lower than the previous study, reported by Mozaffor et al. (2010) and Numan et al. (2005) where the reported the protective titer were 96.67\% and 100\% in Bangladesh and Pakistan. On the other hand, the protective HI titer level (83.8\%) was higher than that reported by Aziz and Ahmed (2010) and Hadipour (2009) who recorded the protective titer were $34.4 \%$ and $37.56 \%$. Ezeokoli et al. (1984) reported $72 \%$ prevalence of antibodies against NDV in free range and $62.9 \%$ in traditionally managed backyard flocks in Nigeria which were also lower than the present study in Bangladesh. In this study, the low level of antibody titers $\left(<2^{3}\right)$ in some vaccinated layer birds might be due to the poor vaccine quality or vaccination failure. In spite of vigorous vaccination schedules, ND is still threat to the poultry industry and even in vaccinated chicken flocks a number of outbreaks have been recorded (Siddique et al., 1986). One of the causes for outbreaks in vaccinated chickens might be the introduction of new ND virus strains against which the local birds have no or very low immunity, leading to vaccine failure. Other factors include poor quality vaccine, poor manufacturing standards, inadequate storage facilities, application of expired vaccine batches, faulty application and vaccine handling during transportation (Vui et al., 2002). Inadequate water supply and heat stress may also lead to production of steroids and thus cause immunosuppression (Sil et al., 2002). Low ND-HI antibody level is suggestive of an inter-epidemic phase or early phase of infection, thus problems with ND outbreaks in the near future may have to be expected unless the vaccination schedule and vaccine practices are improved. 
4.3. Prevalence of ND in vaccinated chickens having specific HI antibody below protective level

In the present study the overall prevalence of Newcastle disease in vaccinated chickens below protective level poultry was found $38.46 \%$ which is higher than previous study report of Hasan et al. (2016), Rahman et al. (2012), Talha et al. (2001), Badruzzaman et al. (2015) and Islam et al. (2003) were they reported 16.61\%, $9.85 \%, 10.24 \%, 13.84 \%$ and $6.73 \%$ respectively. On the other hand, the present finding was less than those reported by Hasan et al. (2012) where they reported $39.1 \%$ and $53.96 \%$ respectively. In the present study, prevalence of ND was higher in layer (40\%) followed by broiler (38.09\%) chickens (Table 6). In case of layer the prevalence of present study is higher than the previous report of Das et al. (2018), Hasan et al. (2012), Islam et al. (2010) and Rahman et al. (2012) where they reported the prevalence were $30.80 \%, 30.68 \%$, $44 \%$ and $25 \%$ in layer. In case of broiler the prevalence of ND was higher than the previous report by Islam et al. (1998), Hasan et al. (2012) and Das et al. (2018) where they reported prevalence of ND were $4.00 \%, 14.89 \%$ and $8.90 \%$ in broiler.

\subsection{Pathology in Newcastle disease virus infected chickens}

In this study, the microscopic lesions showed hemorrhages and necrosis in the mucosa and submucosa of proventiculus, desquamation of proventriculus epithelial layer, globular destruction of proventiculas surface, hyperemia of the muscularis layer and infiltration of inflammatory cells to submucosal layer of proventriculus glands, intestinal villi were blunted and necrosis of sub mucosa and mononuclear cell infiltration in the lamina propria, decreased number of lymphocytes in periarterial lymphotic sheath of spleen, hemorrhages, congestion and necrosis in epithelial mucosal cell of spleen, degeneration and multifocal necrosis in liver of broiler chicken, while in layer chicken they were accompanied by perihepatitis, hemorrhage, necrosis, and multifocal inflammatory cell infiltration in liver, Congestion, edema, and mononuclear inflammatory infiltration at the inside and the wall of alveoli, epicarditis and myocarditis, myocardium degeneration of heart, congestion, hemorrhage, mononuclear inflammatory cell infiltration in subepithelial layer of trachea which have been already reported by Etriwati et al. (2017), Brar et al. (2017) and Pabitra et al. (2016).

\section{Conclusions}

The present study was conducted to evaluate humoral immunity against Newcastle disease (ND) virus in vaccinated chicken serum HI antibody titers and its pathological changes on the basis of gross pathology, histopathological examination and serological study. Total $240(n=240)$ number of serum sample (broiler 135, layer 105) were collected during this study period. According to our results, the overall detection of HI antibodies against Newcastle disease virus was $62.2 \%$ in broiler and $83.8 \%$ in layer chickens. For both broiler and layer chicken's protective antibody titers were found higher in adult than in young chickens. ND is still prevalent in many areas though vaccination has been widely used for prevention and control of the disease. So, to reduce the infection rate of Newcastle disease in chickens, proper biosecurity maintenance, management, limited entrance of rodents and wild birds is essential. To reduce the incidence, management measures and disinfection, along with vaccination are practical to prevent and control. To improve the serum antibody titer poor quality vaccine, poor manufacturing standards, inadequate storage facilities, application of expired vaccine batches, faulty application of vaccine should be avoided.

\section{Acknowledgements}

The authors are cordially grateful to the Department of Pathology and Parasitology, Patuakhali Science and Technology University, Patuakhali, Bangladesh for providing research facilities.

\section{Conflict of interest}

None to declare.

\section{References}

Alexander DJ and RE Gough, 2003. Newcastle Disease and Other Avian Paramyxovirus Infections. In: Saif, Y.M., Barnes, H.J., Glisson, J.R., Fadly, A.M., McDougal, L.R. and Swayne, D.E., Eds., Disease of Poultry, 11th Edition, Iowa State University Press, Ames, 1A, 63-87.

Alders RG, R Costa, P Dias, R Fringe, A Fumo, Q Lobo, BV Mata, A Silva and MP Young, 2001. Investigations into the Control of Newcastle Disease in Village Chickens in Mozambique: Review of work done in Mozambique. Report on the ACIAR/INIVE Newcastle Disease Control Project Coordination Meeting,Tofo, Inhambane Province, Appendix 3. 
Aziz TA and TA Ahmed, 2010. Serological survey of Newcastle disease in domestic chickens in Sulaimani province, Journal of Zankoy Sulaimani, 13: 31-38.

Alexander DJ, 2000. Newcastle disease and other avian paramyxoviruses. Rev. Sci. Tec., 19: 443-462.

Bell JG and S Moulodi, 1988. A reservoir of virulent Newcastle disease virus in village chicken flocks. Prev. Vet. Med., 6: 37-42.

Badruzzaman ATM, M Noor, MA Mamun, A Husna, KM Islam, KJ Alam and MM Rahman, 2015. Prevalence of diseases in commercial chickens at Sylhet division of Bangladesh. Int. Clin. Pathol. J., 1: 00023.

Brar RS, Leishangthem, D Geeta, PD Gadhave, ND Singh, HS Banga, V Mahajan and S Sodhi, 2017. Diagnosis of Newcastle disease in broiler by histopathology and immunohistochemistry. Indian J. Vet. Pathol., 41: 6062.

Das A, P Ghosh, A Sen, A Das and S Chowdhury, 2018. A retrospective analysis of prevalence of Newcastle disease and infectious bursal disease in poultry at Kishoreganj. Bangladesh. J. Vet. Med. Health, 2: 108.

Ezeokoli CD, JU Umoh, AA Adesiyun and PA Abdu, 1984. Prevalence of Newcastle disease virus antibodies in local and exotic chickens under different management sytems in Nigeria. Bulletin of Animal Health and Production in Africa, 32: 253- 257.

Etriwati RD, E Handharyani and S Setiyaningsih, 2017. Pathology and immunohistochemistry study of Newcastle disease field case in chicken in Indonesia. Vet. World, 10: 1066-1071.

Husna A, ATM Badruzzaman, MS Islam, NS Runa, S Yesmin and MM Rahman, 2016. Evaluation of humoral immunity against Newcastle disease virus in vaccinated chickens at Dhaka and Narayanganj districts of Bangladesh. J. Vet. Anim. Sci., 3: 2313-5514.

Hadipour MM, 2009. A serological survey for Newcastle disease virus antibodies in backyard chickens around Maharlou Lake in Iran. J. Anim. Vet. Adv., 8: 59-61.

Hasan MK, MH Kabir, MAA Hasan, S Sultana, MSI Khokon and SM Kabir, 2016. Prevalence of poultry diseases in Gazipur district of Bangladesh. Asian J. Med. Biol. Res., 2: 107-112.

Hasan AR, M Ali, M Siddique, M Rahman and M Islam, 2012. Clinical and laboratory diagnoses of Newcastle and Infectious bursal diseases of chickens. Bangl. J. Vet. Med., 8: 131- 140.

Islam MR, BC Das, K Hossain, NS Lucky and MG Mostafa, 2003. A Study on the occurrence of poultry diseases in Sylhet region of Bangladesh. Int. J. Poult. Sci., 2: 354-356.

Islam MA, MH Haque, MT Hossain, MT Islam, MA Zinnah and MSR Khan, 2010. Isolation and detection of Newcastle disease virus from field outbreaks in broiler and layer chickens by reverse transcriptionpolymerase chain reaction. J. Vet. Med., 8: 87-92.

Islam MR, MAHNA Khan, PM Das and ASM Bari, 1998. Poultry diseases diagnosed at necropsy in 1997 and 1998 in the Department of Pathology of Bangladesh Agricultural University, Mymensingh. Proceedings of 5th BSVER Annual Scientific Conference held on 3-4 December, 1998, at Bangladesh Agricultural University, Mymensingh.

Illango J, A Etoori, M Olupot and J Mabonga, 2003. Rural poultry production in two Agro- ecological zones of Uganda. Paper present at the second research coordinated meeting on family poultry production in Africa, Morogoro Tanzania.

Kumar P, S Rashid, MH Ali, H Mobarak, MA Islam and R Haydar, 2016. Prevalence and pathology of Newcastle disease in broiler at Bochaganj Upazila of Dinajpur, Bangladesh. Asian J. Med. Biol. Res., 2: 352356.

Martinez JC, WK Chou, LR Berghman and JB Carey, 2018. Evaluation of the effect of live LaSota Newcastle disease virus vaccine as primary immunization on immune development in broilers. Poult. Sci., 97: 455-462.

Mozaffor KM, MY Ali and I Yamato, 2010. Antibody levels against Newcastle disease virus in chickens in Rajshahi and surrounding districts of Bangladesh. Int. J. Biol., 2: 102-106.

Maeda T, Y Shintani, K Nakano, K Terashima and Y Yama-da, 2004. Failure of inactivated influenza A vaccine to protect healthy children aged 6-24 months. Pediatrics International, 46: 122-125.

Munir M, S Zohari, M Abbas and M Berg, 2012. Sequencing and analysis of the complete genome of Newcastle disease virus isolated from a commercial poultry farm in 2010. Arch. Virol., 157: 765-768.

Numan M, MA Zahoor, HA Khan and M Siddique, 2005. Serological status of Newcastle disease in broilers and layers in Faisalabad and surrounding districts. Pak. Vet. J., 25: 55-58.

OIE, 2012. Newcastle disease. Manual of Diagnostic Tests and Vaccines for Terrestrial Animals. Chapter 2: 3.14.

Rahman MS, MG Rabbani, MJ Uddin, A Chakrabartty and Her Moon, 2012. Prevalence of avian influenza and Newcastle disease viruses in poultry in selected areas of Bangladesh using rapid antigen detection kit. Med Pub Journals, 3: 1-3. 
Saif YM, 1998. Infectious bursal disease and hemorrhagic enteritis. Poult. Sci., 77: 1186-1189.

Sil GC, PM Das, MR Islam and MM Rahman, 2002. Management and disease problems of cockerels in some farms of Mymensingh, Bangladesh. Int. J. Poult. Sci., 1: 102-105.

Siddique M, MA Sabri and MZ Khan, 1986. Outbreaks of Newcastle disease in vaccinated flocks in and around Faisalabad. Pak. Vet. J., 6: 41-45.

Tu TD, KV Phuc, NTK Dinh, DN Quoc and PB Spradbrow, 1998. Vietnam trials with a thermostable vaccine (strain I2) in experimental and village chickens. Prev. Vet. Med., 34: 205-214.

Titford M, 2009. Progress in the development of microscopical techniques for diagnostic pathology. J. Histotechnol., 32: 9-19.

Talha AFSM, MM Hossain, EH Chowdhury, ASM Bari and MR Islam, 2001. Poultry diseases occurring in Mymensingh district of Bangladesh. Bangl. Vet. J., 18: 20-23.

Veits J, D Wiesner, W Fuchs, B Hoffmann, H Granzow, E Starick, E Mundt, H Schirmer, T Mebatsion, TC Metten-leiter and A Romer-Oberdorfer, 2006. Newcastle disease virus expressing H5 hemagglutinin gene protects chickens against New-castle disease and avian influenza. Proc. Natl. Acad. Sci. USA, 10: 81978202.

Vui TQ, JE Lohr, MN Kyule, KH Zessin and MPO Baumann, 2002. Antibody levels against Newcastle disease virus, Infectious bursal disease virus and Influenza virus in rural chicks in Vietnam. Int. J. Poult. Sci., 1: 127132. 